\title{
The Effect of Technostress on Emotional Exhaustion and Coping Strategies
}

Erne Suzila Kassim, Sharifah Fazirah Syed Ahmad, Arif Hisyamuddin Bahari, Fatin Nadhirah Mohammad Fadzli, Nor Syafiqah Haila Mohamad Adzmi

To Link this Article: http://dx.doi.org/10.6007/IJARBSS/v11-i5/9856 DOI:10.6007/IJARBSS/v11-i5/9856

Received: 02 April 2021, Revised: 28 April 2021, Accepted: 16 May 2021

Published Online: 23 May 2021

In-Text Citation: (Kassim et al., 2021)

To Cite this Article: Kassim, E. S., Ahmad, S. F. S., Bahari, A. H., Fadzli, F. N. M., \& Adzmi, N. S. H. M. (2021). The Effect of Technostress on Emotional Exhaustion and Coping Strategies. International Journal of Academic Research in Business and Social Sciences, 11(5), 544-559.

Copyright: @ 2021 The Author(s)

Published by Human Resource Management Academic Research Society (www.hrmars.com) This article is published under the Creative Commons Attribution (CC BY 4.0) license. Anyone may reproduce, distribute, translate and create derivative works of this article (for both commercial and non-commercial purposes), subject to full attribution to the original publication and authors. The full terms of this license may be seen at: http://creativecommons.org/licences/by/4.0/legalcode

Vol. 11, No. 5, 2021, Pg. 544 - 559

Full Terms \& Conditions of access and use can be found at http://hrmars.com/index.php/pages/detail/publication-ethics 


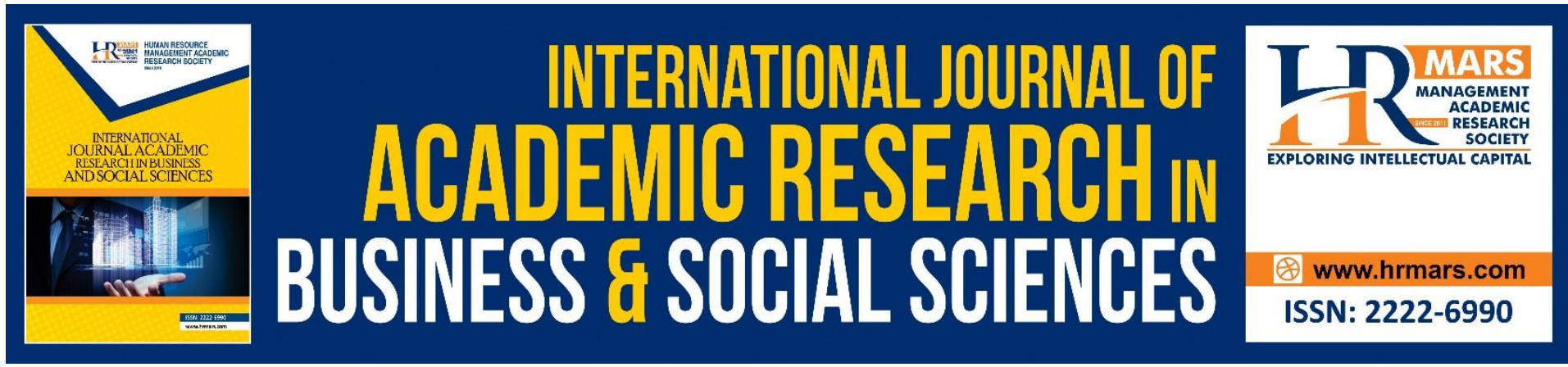

\title{
The Effect of Technostress on Emotional Exhaustion and Coping Strategies
}

\author{
Erne Suzila Kassim \\ Associate Professor Faculty of Business and Management Universiti Teknologi Mara \\ Kampus Puncak Alam Malaysia \\ Sharifah Fazirah Syed Ahmad \\ Senior Lecturer Faculty of Business and Management Universiti Teknologi Mara \\ Kampus Puncak Alam Malaysia \\ Corresponding Author
}

\begin{abstract}
Arif Hisyamuddin Bahari, Fatin Nadhirah Mohammad Fadzli, Nor Syafiqah Haila Mohamad Adzmi

Faculty of Business and Management, Universiti Technology MARA 42300, Puncak Alam, Selangor
\end{abstract}

\begin{abstract}
Technostress at a workplace is a negative consequence of not being able to adapt adequately to technology rapid advancement. It may cause psychological disturbance to the employees and lead to many disturbing effects such as job dissatisfaction, job isolation and emotional exhaustion. While past studies have examined the causal direction of technostress to employees' behavior, this study explores the relationship between technostress and emotional exhaustion and coping strategy, measured as proactive and reactive coping among office personnel. A survey was conducted among 140 employees from various organizations, who were selected based on convenience sampling. The data was analysed using SmartPLS for both measurement and structural model. The results suggest there are significant relationships between technostress and emotional exhaustion, between technostress and reactive coping, and between emotional exhaustion and both proactive and reactive coping strategy. The relationship between technostress and proactive coping was found to be not significant. The findings suggest even though technostress leads to emotional exhaustion, how employees cope the mental challenge require further investigations. The study is significance as a pathway to look for adequate strategies and creating awareness on the potential emotional burdens caused by technostress.

Keywords: Technostress, Technostress and Emotional Exhaustion, Technostress and Coping Strategy, Information Technology and Mental Health, It and Quality of Life.
\end{abstract}




\section{Introduction}

\section{Background}

Open People are now living in a digital era, in which use of information technology in the workplace has become almost necessary for the organization operations. This is due to the fact that computers are everywhere. Technology has become essential in conducting day-today work and also for communication purposes. As the role of technology is being redefined and is constantly being improved, change is inevitable (Prabhakaran \& Mirsha, 2012). As a result, the user needs to be literate in order to fully utilize the benefits of technological advancement. Consequently, tension occurs when users are unable to adapt and cope with the technology usage that causes detrimental consequences on the user's physical and psychological well-being. Therefore, the term 'technostress' has emerged and been related to the usage of computer technology since the early of the modern computer creation until now. The symptoms of ICT-related techno-stress include panic, anxiety, resistance, technophobia, mental fatigue, physical ailments, intolerance and perfectionism, headaches, joint aches and insomnia (Ansah et al., 2016). The workforce has been forced or it is a mandatory to learn how to use new modern technologies that continuously experiencing revolution of computer invention. Just like an update from apps, so does the people. People need to keep updating their knowledge about current technologies from time to time without fail. This matter has led to the emergence of technostress in relation with emotional exhaustion that creates a chronic state of physical and emotional giving out that results from the excessive job and or personal demands and continuous stress (Qureshi \& Sajjad, 2015). Technostress causes a psychological disturbance to the user when they found technology is practically complex and rapid. Technostress results when there is an imbalance between users and their environment (Weinert et al., 2019). Technostress terms were invented in the year 1984 by Dr. Craig Brod (Prabhakaran \& Mirsha, 2012) (Brod, 1984). The term technostress emerged more than two decades ago to describe stress reactions in relation to technology (Ansah et al., 2016). It causes a negative dissonance on organizational financial, risk in organization investment and employee psychologically well-being. Technostress should be controlled though, it is inevitable, and this is because employee well-being is vital for organization continuous achievement.

Technostress has been studied from various perspectives and purposes. It has been studied in relation to personality (Korzynski et al., 2020) and (Maier, 2015), within the education and academic performance (Hsiao et al., 2017) and job performance among academics (Christian et al., 2020). Studies have also found excessive use of technology could create negative consequences to the mental health (Fujimoto et al., 2016). Likewise, the use of technology without a clear boundary and the unsustainable working conditions have created tensed situations to employees and lead to exhaustion (Molino et al. 2019). As use of technology has become a norm, but its usage may signal for emotional exhaustion, this study was conducted to explore the relationship between technostress and emotional exhaustion, and to explore in what capacity employees cope with the issue, either proactive or reactive coping is taken as a measure to reduce the stress.

\section{Literature Review}

This section discusses about the relationships between technostress and emotional exhaustion. It starts with the discussion on the relationship between technostress and coping strategies, followed by emotional exhaustion. 


\section{Technostress}

The term "technostress" is defined as "a modern disease of adaptation caused by an inability to cope with the new computer technologies in a healthy manner" (Brod, 1984). Technostress is stated as the stress one feels when technology takes center stage in our work lives, home environments and at play (Michelle and Larry, 1998). One research simply defines the technostress as "resistance to change" (Clark and Kalin, 1996). Technostress is about the illness that people are facing up when they adapt to technology. On the other hand, the term technostress also to include "any negative impact on attitudes, thoughts, behaviors or psychology caused directly or indirectly by technology" (Rosen and Weil, 1997). (Caro and Sethi, 1985) said that the stress that caused by the technology was termed as technostress and is also known as technophobia, cyber phobia, computer-anxiety and also computer stress. The significance of the learning technostress is we can explore on how to adapt with technology in a proper way without having stress, changes in thoughts, behaviors and even more.

\section{Emotional Exhaustion}

Emotional exhaustion comes from accumulated stress by individuals who cannot overcome it. By suffering from emotional exhaustion, it can cause permanent damage to their health. The research work introduced emotional exhaustion as the state of depletion and fatigue that is considered the main component of job burnout (Maslach and Jackson, 1981); (Wright and Cropanzano, 1998). While on the other article says, emotional exhaustion is associated with a host of somatic difficulties, such as colds, gastro-intestinal problems, headaches and sleep disturbances (Belcastro, 1982; Belcastro and Hays, 1984). It is also known as an exploratory factor of burnout. It is reported as one of the most important dimensions of burnout and is widely analyzed (Halbesleben and Bowler, 2007). On the other hand, emotional exhaustion is defined as "a consequence of intense physical, affective and cognitive strain, such as a longterm consequence of prolonged exposure to certain job demands" (Demerouti et. al., 2010). The term emotional exhaustion is one of the most important study among general practitioners for the reason to provide cure of the illnesses beforehand as well as thinking for ways to prevent it.

\section{Coping Theory}

This study has used coping theory to further comprehend the responses towards technostress. Coping is the process through which the individual manages the demands of the person-environment relationship that are appraised as stressful and the emotions they generate (Lazarus and Folkman, 1984). The author from the same study defined coping as constantly changing cognitive and behavioral efforts to manage specific external and/or internal demands that are appraised as taxing or exceeding the resources of the person. There are coping strategies that can be used to manage psychological stress to avoid disequilibrium. Coping acts as a powerful mediator of emotional outcomes; positive outcomes are associated with some coping strategies, negative outcomes with others (Lazarus, 1993). Coping is used to lower psychophysiological dissonance to regulate unpleasant environmental conditions. It is able to cause a magnitude variance in individual adaptation outcome. Neutralizing a dangerous or noxious condition are learned behavioral responses that are needed to successfully in lowering negative arousal. Coping were in the basis of process-oriented rather than trait-oriented as situation continuously changing and possessed precise demands and conflicts. Also, coping theory highlighted its differences from an automatized adaptive 
behavior. It allows any actions and thoughts from the individual as it is an effort to manage unpleasant condition regardless of how it will succeed (Lazarus and Folkman, 1984).

\section{Strategies}

Coping strategies are types of conscious adaptive responses consistently applied to a broad range of stressful events (Dwyer and Cummings, 2001). It portrays individual's attitudes in handling various noxious event and attack. Various coping modes exist for instance, humor, crying, cursing, talking it out, thinking through and get rid of noxious situation by tiring oneself. However, according to (Lazarus, 1993), the coping strategies for anticipating an event's occurrence are often incompatible with strategies needed to anticipate the event's nonoccurrence. Coping strategies is essential to let individuals able to adjust to the upcoming threat with the information about coping strategies they received (Lazarus and Folkman, 1984). There were two coping strategies discuss in this section which are proactive and reactive coping strategies.

\section{Proactive Coping}

The concept and theory of proactive coping and preventive coping comes from the theoretical tradition of Lazarus and other researchers. Through proactive coping strategies individuals take practical precaution and determined their actions. Proactive coping is defined as efforts to strive actively to seek new challenges, create new opportunities, and facilitate promotion toward challenging goals so that they will be less negative. Proactive coping based on challenges forecasted as they deal with stressful conditions that have not occurred in real life setting. Goal of proactive coping is to reduce potential risk factors or changing management skills the nature of the stressor before workers experience stress-related symptoms or disease (La Montagne et al., 2007). It also introduces about proactive coping, proactive coping is a multidimensional, forward-looking strategy, integrating processes of personal quality-of-life management with those of self-regulatory goal attainment (Greenglass and Fiksenbaum, 2009).

\section{Reactive Coping}

Reactive coping strategy aims at restoring the users' strained emotional state back to normal but does not address the original techno-stressor (Weinert et al., 2019). In reactive coping the individual reacts to a stressor that he has already encountered and works to reduce the ensuing stress. Traditional coping models have emphasized the reactive nature of coping while proactive coping is a newer concept (Rai et al.,2019). In contrast, those who use reactive coping are less flexible and more likely to act in response to changes. A reactive coping response occurs after the stressor, while a proactive coping response aims to head off a future stressor. According to (La Montagne et al., 2007), the goal of reactive coping is to treat, compensate, and rehabilitate stress workers with enduring stress-related symptoms or disease. For that reason, reactive coping is defined as an effort to deal with a past or present stressful encounter, or to compensate for or accept harm or loss (Schwarzer and Knoll, 2003).

\section{Relationships between the Variables Technostress and Emotional Exhaustion}

According to (Brod, 1984), he defined technostress as "a modern disease of adaption caused by an inability to cope with the new computer technologies in a healthy manner". The usage of a computer or work which demand people to use IT in completing any daily task has made 
people tumble into a psychological state of stress (Maier, 2015). The formation of technostress is happened due to the presence and intensity of the technostressors which can be seen in any workplace that uses computers (Srivastava et al., 2015). According to Gaudioso, et al., (2017), there are some technologies that can be so invasive that can lead employees to sense techno-invasion. Techno-invasion is as defined by them, "a sense of technology intrusiveness, which blurs desired boundaries between work and other life domains." The effect of technostress to the emotional exhaustion has been discussed by (Tarafdar, et al., 2013), technostress can have indirect lead to i) higher work pressures, ii) perceptions of work overload, iii) information fatigue, frustration, iv) demoralization, v) loss of motivation, vi) job burnout and many more.

Hence, it is assumed:

H1: There is a relationship between technostress and emotional exhaustion

\section{Technostress and Coping Strategies}

According to (Beaudry and Pinsonneault, 2005) (Lazarus and Folkman, 1984), the coping strategies available in overcoming technostress can give an option to choose between proactive and reactive coping strategies. In addition, these coping strategies can anticipate or prevent technostress from happening. Usually, people will cope with technostress by using these two that have influenced each other (Lazarus, 1966) (Lazarus and Folkman, 1984).

The coping model of user adaptation is defined by (Wanda and Marcie, 1994) as "modifications brought to the technology, working procedures, and users' beliefs." While (Beaudry and Pinsonneault, 2005) believed user adaptation and coping is the same thing and defined it as "the cognitive and behavioral efforts exerted by users to manage specific consequences associated with a significant IT event that occurs in their work environment." For instance, the usage of any two of the coping strategies either proactive or reactive coping strategies will determine on how individual to cope with technostress. Therefore, two hypotheses were developed:

$\mathrm{H} 2$ : $\quad$ There is a relationship between technostress and proactive coping

H3: $\quad$ There is a relationship between technostress and reactive coping

\section{Emotional Exhaustion and Coping Strategies}

According to (Maier, 2015), the usage of IT has an influence on an individual's emotional exhaustion because of technostress. Emotional exhaustion is the feeling of tension and depletion of one's emotional resources (Maslach and Jackson, 1981), (Moore, 2000). While, based on the coping model of user adaptation by (Beaudry and Pinsonneault, 2005), stated that user adaptation and coping is the same thing and defined it as "the cognitive and behavioral efforts exerted by users to manage specific consequences associated with a significant IT event that occurs in their work environment." Emotional exhaustion happens due to the technostress and will have a direct impact on determining the coping strategies by individual affected by that matter (Srivastava et al., 2015), (Beaudry and Pinsonneault, 2005). Thus, this study undertakes that;

$\mathrm{H} 4$ : There is a relationship between emotional exhaustion and proactive coping

$\mathrm{H} 5$ : There is a relationships between emotional exhaustion and reactive coping 
Figure1 Proposed Conceptual Framework

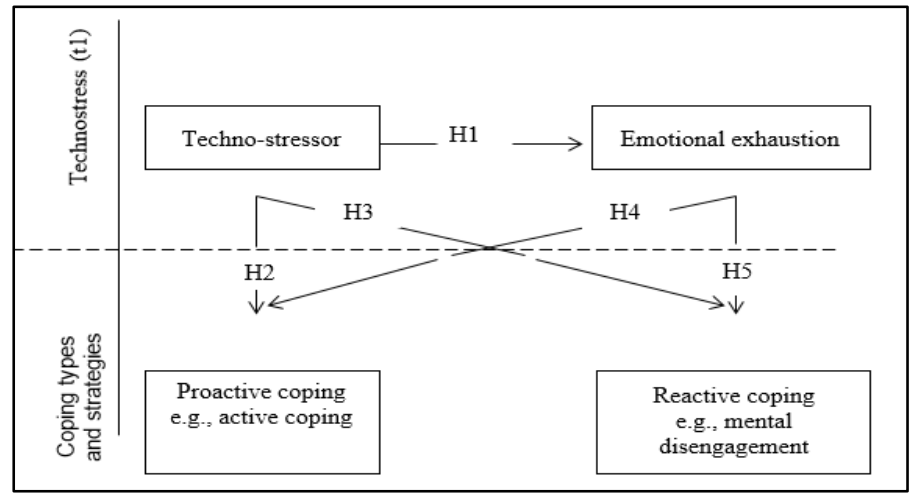

\section{Methodology}

The study was conducted as a correlational research, with office workers as the population. Using the convenience sampling method, data was collected using online survey. A total of 140 dataset was used and the sample size is considered appropriate for Smart PLS analysis (Hair et al., 2011). The item measurement was adopted from (Weinert et al., 2019). The technostress construct was measured as innovation privacy, work overload, job insecurity, role ambiguity and work-home conflict. The measurement was validated by two experts in the field of management and human resource. In addition, a pilot test was conducted before the actual data collection, which is to allow for a revised and valid questionnaire. Thirty respondents took part in the pilot test, and they provided feedback on the patterns and standardization of the wording, choice of words and simplicity of the questionnaire. The results of the internal consistency score yield Cronbach alpha for all measures were above 0.700 . Hence, assumption of the item reliability was met.

\section{Respondents Profile}

The respondents consisted of 58 males (41.4\%) and 82 females (58.6\%). In terms of the age category, 43 of the respondents aged between $18-25$ years old (30.7\%), 63 of them aged between $26-35$ years old (45\%), 20 of them were in the age category of between 36 and 45 years old (14.3\%) and 14 of them aged between 46 to 60 years old (10\%). $47.1 \%$ of them were single (66) and the other 77 respondents were married (52.9\%). Majority of the respondents have obtained a university degree $(60 \%)$ and $25 \%$ of them have at least a college diploma. In relation to work experience, almost half of the respondents $(49.3 \%)$ have been in the workforce for less than 5 years, and $20 \%$ of them have the experience between 6 to 10 years.

\section{Validity and Reliability}

SmartPLS ver 3.3.2 was used for running the measurement and structural models. To confirm on the measurement validity and reliability, result for the indicator loading, the internal consistency of cronbach's alpha (CA), composite reliability (CR) and the average variance extraction (AVE) for the reflective constructs were obtained. They are shown in Table 1 below. The initial analysis of the PLS algorithm yield results of the average variance extraction (AVE) for both job insecurity and reactive coping were less than 0.500 . Then the item loadings for these two measures were checked. In order to improve on the measurement validity, two items for each measure were deleted. These items were J1 "IT will advance to an extent where my present job can be performed by a less skilled individual", J3 "I believe that IT make it easier for other people to perform my work activities", RC1 "I turn to work or other substitute activities to take my mind off things" and RC2 "I go to movies or watch TV, to think about it 
less". Based on the results in Table 1, all scores meet the minimum recommended value as suggested by (Hair et al., 2011).

Table 1: The Measurement Model

\begin{tabular}{|c|c|c|c|c|c|c|}
\hline Construct and Item & Mean & $\begin{array}{l}\text { Standard } \\
\text { Deviation }\end{array}$ & Loading & $\begin{array}{l}\text { Cronbach's } \\
\text { Alpha }\end{array}$ & CR & AVE \\
\hline Privacy Invasion (PI) & & & & 0.843 & 0.892 & 0.677 \\
\hline $\begin{array}{l}\text { 1. I feel uncomfortable that } \\
\text { my use of IT can be easily } \\
\text { monitored. }\end{array}$ & 3.600 & 1.020 & 0.787 & & & \\
\hline $\begin{array}{l}\text { 2. I believe that my privacy } \\
\text { can be violated because } \\
\text { the activities with IT can } \\
\text { be easily tracked. }\end{array}$ & 3.843 & 1.071 & 0.891 & & & \\
\hline $\begin{array}{l}\text { 3. I believe that the use of } \\
\text { IT makes it easier to } \\
\text { invade my privacy. }\end{array}$ & 3.721 & 1.008 & 0.904 & & & \\
\hline $\begin{array}{l}\text { 4. I feel my employer could } \\
\text { violate my privacy by } \\
\text { tracking my activities } \\
\text { using ITs }\end{array}$ & 3.657 & 1.005 & 0.691 & & & \\
\hline Work Overload (WO) & & & & 0.822 & 0.877 & 0.642 \\
\hline $\begin{array}{l}\text { 1. I believe that the number } \\
\text { of requests, problems or } \\
\text { complaints I deal with is } \\
\text { more than expected. }\end{array}$ & 3.336 & 0.997 & 0.731 & & & \\
\hline $\begin{array}{l}\text { 2. I believe that the amount } \\
\text { of work I do interferes } \\
\text { with how well it is done. }\end{array}$ & 3.314 & 1.063 & 0.772 & & & \\
\hline 3. I feel busy or rushed. & 3.264 & 1.080 & 0.865 & & & \\
\hline 4. I feel pressured. & 2.807 & 1.075 & 0.829 & & & \\
\hline Role Ambiguity (RA) & & & & 0.867 & 0.909 & 0.714 \\
\hline $\begin{array}{l}\text { 1. I am unsure whether I } \\
\text { have to deal with IT } \\
\text { problems or with my } \\
\text { work activities. }\end{array}$ & 2.721 & 0.911 & 0.838 & & & \\
\hline $\begin{array}{l}\text { 2. I am unsure what to } \\
\text { prioritize: dealing with IT } \\
\text { problems or my work } \\
\text { activities. }\end{array}$ & 2.757 & 0.948 & 0.856 & & & \\
\hline $\begin{array}{l}\text { 3. I can not allocate time } \\
\text { properly for my work } \\
\text { activities because my } \\
\text { time spent on IT- } \\
\text { activities varies. }\end{array}$ & 2.786 & 1.020 & 0.856 & & & \\
\hline $\begin{array}{l}\text { 4. Time spent resolving IT } \\
\text { problems takes time }\end{array}$ & 2.921 & 1.122 & 0.829 & & & \\
\hline
\end{tabular}




\section{Construct and Item
away from fulfilling my
work responsibilities.}

Work-home Conflict (WHO)

1. Using IT blurs boundaries between my job and my home life.

2. Using IT for work-related responsibilities creates conflicts with my home responsibilities.

3. I do not get everything done at home because I find myself completing job-related work due to IT.

4. My spouse/family ever get frustrated with me because I am spending time at home doing work

Job Insecurity (JI)

1. I am worried that new IT may pose a threat to my job.

2. I do not share my knowledge with my coworkers for fear of being replaced.

\section{Emotional Exhaustion (EE)}

1. I feel drained from activities that require me to use IT.

2. I feel tired from my IT activities.

3. Working all day with ITs is a strain for me.

4. I feel burned out from my IT activities.

Proactive Coping (PC)

1. I take additional action to try to get rid of the IT problem.

2. I concentrate my efforts in doing something about the IT problem.

Mean $\begin{aligned} & \text { Standard } \\ & \text { Deviation }\end{aligned}$ Loading $\begin{aligned} & \text { Cronbach's } \\ & \text { Alpha }\end{aligned} \quad$ CR $\quad$ AVE

0.840

0.894

0.682
0.919

$\begin{array}{lll}2.686 & 1.070 & 0.816\end{array}$

\section{$\begin{array}{lll}3.229 & 1.179 & 0.668\end{array}$}

0.484

0.7910 .656

$\begin{array}{lll}2.936 & 1.110 & 0.746\end{array}$

$\begin{array}{lll}2.114 & 1.089 & 0.870\end{array}$

$\begin{array}{lll}2.664 & 1.032 & 0.883\end{array}$

0.938

$0.956 \quad 0.844$

0.952

0.871

$0.910 \quad 0.716$

$\begin{array}{lll}3.279 & 0.895 & 0.826\end{array}$ 


\begin{tabular}{lllllll}
\hline Construct and Item & Mean & $\begin{array}{l}\text { Standard } \\
\text { Deviation }\end{array}$ & Loading & $\begin{array}{l}\text { Cronbach's } \\
\text { Alpha }\end{array}$ & CR & AVE \\
\hline $\begin{array}{l}\text { 3. I do at any time what } \\
\text { needs to be done to get }\end{array}$ & 3.464 & 0.937 & 0.899 & & & \\
$\begin{array}{l}\text { rid of the IT problem. } \\
\text { I take direct action to get }\end{array}$ & 3.536 & 0.882 & 0.810 & & & \\
$\begin{array}{l}\text { around the IT problem. } \\
\text { Reactive Coping (RC) }\end{array}$ & & & & 0.469 & $\mathbf{0 . 7 7 2}$ & $\mathbf{0 . 6 3 6}$ \\
$\begin{array}{l}\text { 1. I daydream about things } \\
\text { other than this. }\end{array}$ & 3.107 & 1.033 & 0.645 & & & \\
$\begin{array}{l}\text { 2. I sleep more than usual. } \\
\text { I } 2.871\end{array}$ & 1.081 & 0.925 & & & \\
\hline
\end{tabular}

The next procedure for the discriminant validity was running the Fornell \& Lacker's criterion and assessing the cross-loading criterion. The results are shown in Table 2 and Table 3 respectively. The results of the Fornell \& Lacker's criterion shown the square root of the AVE of the construct is larger than the correlations between the construct and other constructs in the model.

Table 2: Fornell \& Lacker's Criterion

\begin{tabular}{lllllllll}
\hline & EE & JI & $\mathbf{p}$ & PC & RC & RA & WHC & WO \\
\hline EE & $\mathbf{0 . 9 1 9}$ & & & & & & & \\
JI & 0.424 & $\mathbf{0 . 8 1 0}$ & & & & & & \\
P & 0.368 & 0.329 & $\mathbf{0 . 8 2 3}$ & & & & & \\
PC & 0.302 & 0.133 & 0.227 & $\mathbf{0 . 8 4 6}$ & & & & \\
RC & 0.381 & 0.437 & 0.254 & 0.160 & $\mathbf{0 . 7 9 7}$ & & & \\
RA & 0.527 & 0.497 & 0.425 & 0.193 & 0.374 & $\mathbf{0 . 8 4 5}$ & & \\
WHC & 0.559 & 0.435 & 0.427 & 0.304 & 0.442 & 0.628 & $\mathbf{0 . 8 2 6}$ & \\
WO & 0.475 & 0.308 & 0.389 & 0.249 & 0.242 & 0.498 & 0.473 & $\mathbf{0 . 8 0 1}$ \\
\hline
\end{tabular}

The results of the cross loading in Table 3 suggest all items are in the respective construct. The loadings of each indicator are the highest for their designated constructs. 
Table 3: Cross Loadings

\begin{tabular}{lllllllll}
\hline & EE & $\mathrm{Jl}$ & $\mathrm{P}$ & $\mathrm{PC}$ & $\mathrm{RC}$ & $\mathrm{RA}$ & $\mathrm{WHC}$ & $\mathrm{WO}$ \\
\hline IP_1 & 0.251 & 0.243 & $\mathbf{0 . 7 8 7}$ & 0.155 & 0.195 & 0.338 & 0.346 & 0.344 \\
IP_2 & 0.317 & 0.256 & $\mathbf{0 . 8 9 1}$ & 0.146 & 0.249 & 0.337 & 0.319 & 0.293 \\
IP_3 & 0.403 & 0.310 & $\mathbf{0 . 9 0 4}$ & 0.219 & 0.256 & 0.413 & 0.447 & 0.350 \\
IP_4 & 0.161 & 0.291 & $\mathbf{0 . 6 9 1}$ & 0.272 & 0.071 & 0.297 & 0.249 & 0.317 \\
JI_2 & 0.289 & $\mathbf{0 . 7 4 6}$ & 0.367 & 0.190 & 0.329 & 0.406 & 0.398 & 0.308 \\
JI_4 & 0.390 & $\mathbf{0 . 8 7 0}$ & 0.195 & 0.049 & 0.378 & 0.405 & 0.324 & 0.210 \\
PC_1 & 0.280 & 0.148 & 0.184 & $\mathbf{0 . 8 2 6}$ & 0.166 & 0.276 & 0.317 & 0.348 \\
PC_2 & 0.199 & 0.055 & 0.183 & $\mathbf{0 . 8 4 7}$ & 0.149 & 0.099 & 0.233 & 0.186 \\
PC_3 & 0.323 & 0.125 & 0.232 & $\mathbf{0 . 8 9 9}$ & 0.140 & 0.166 & 0.270 & 0.188 \\
PC_4 & 0.155 & 0.103 & 0.146 & $\mathbf{0 . 8 1 0}$ & 0.060 & 0.045 & 0.164 & 0.050 \\
RA_1 & 0.374 & 0.382 & 0.323 & 0.197 & 0.302 & $\mathbf{0 . 8 3 8}$ & 0.422 & 0.440 \\
RA_2 & 0.498 & 0.439 & 0.356 & 0.150 & 0.307 & $\mathbf{0 . 8 5 6}$ & 0.437 & 0.456 \\
RA_3 & 0.473 & 0.410 & 0.370 & 0.184 & 0.345 & $\mathbf{0 . 8 5 6}$ & 0.650 & 0.420 \\
RA_4 & 0.416 & 0.443 & 0.385 & 0.126 & 0.310 & $\mathbf{0 . 8 2 9}$ & 0.607 & 0.363 \\
RC_3 & 0.189 & 0.367 & 0.188 & 0.095 & $\mathbf{0 . 6 4 5}$ & 0.373 & 0.395 & 0.170 \\
RC_4 & 0.380 & 0.362 & 0.223 & 0.152 & $\mathbf{0 . 9 2 5}$ & 0.281 & 0.354 & 0.217 \\
EE_1 & $\mathbf{0 . 8 8 3}$ & 0.447 & 0.338 & 0.248 & 0.391 & 0.469 & 0.445 & 0.365 \\
EE_2 & $\mathbf{0 . 9 5 2}$ & 0.380 & 0.331 & 0.282 & 0.377 & 0.509 & 0.529 & 0.472 \\
EE_3 & $\mathbf{0 . 9 1 5}$ & 0.329 & 0.337 & 0.308 & 0.300 & 0.461 & 0.507 & 0.489 \\
EE_4 & $\mathbf{0 . 9 2 3}$ & 0.404 & 0.348 & 0.272 & 0.330 & 0.495 & 0.568 & 0.419 \\
WHC_1 & 0.432 & 0.400 & 0.394 & 0.294 & 0.411 & 0.488 & $\mathbf{0 . 8 7 9}$ & 0.358 \\
WHC_2 & 0.536 & 0.422 & 0.382 & 0.330 & 0.380 & 0.576 & $\mathbf{0 . 9 1 9}$ & 0.449 \\
WHC_3 & 0.493 & 0.389 & 0.357 & 0.139 & 0.399 & 0.601 & $\mathbf{0 . 8 1 6}$ & 0.381 \\
WHC_4 & 0.358 & 0.186 & 0.267 & 0.244 & 0.254 & 0.376 & $\mathbf{0 . 6 6 8}$ & 0.371 \\
WO_1 & 0.276 & 0.197 & 0.287 & 0.249 & 0.169 & 0.370 & 0.349 & $\mathbf{0 . 7 3 1}$ \\
WO_2 & 0.246 & 0.147 & 0.355 & 0.168 & 0.092 & 0.387 & 0.356 & $\mathbf{0 . 7 7 2}$ \\
WO_3 & 0.404 & 0.260 & 0.391 & 0.266 & 0.197 & 0.352 & 0.406 & $\mathbf{0 . 8 6 5}$ \\
WO_4 & 0.499 & 0.321 & 0.249 & 0.141 & 0.261 & 0.473 & 0.398 & 0.829 \\
\hline & & & & & & & &
\end{tabular}

\section{Result and Discussion}

The results of the path coefficients of one tail analysis with t-value $>1.645$ are shown in Table 4. Based on the results, there is a significant relationship between technostress and emotional exhaustion $(\beta=0.809, t=28.274)$, between technostress and reactive coping $(\beta=0.548, t=$ 3.403), emotional exhaustion and proactive coping $(\beta=0.302, t=3.017)$ and emotional exhaustion and reactive coping $(\beta=0.381, t=5.545)$. However, the relationship between technostress and reactive coping was not significant $(\beta=0.281, t=1.554)$. Technostress explain $65.5 \%$ of the variance in emotional exhaustion $\left(R^{2}=0.655\right)$. Emotional exhaustion and technostress explain $11.8 \%$ of the variance in proactive coping $\left(R^{2}=0.118\right)$ and $22.8 \%$ of the variance $=$ in reactive coping $\left(R^{2}=0.228\right)$. In linking each techno-stressor to emotional exhaustion, it was found work-home conflict to be the strongest predictor to emotional exhaustion $(\beta=0.278, t=2.617)$, followed by work overload because of the technology availability $(\beta=0.198, t=2.094)$ and the feeling of insecure towards the job because of the technology $(\beta=0.146, t=1.677)$. The perception of how technology invades the privacy $(\beta=$ $0.058, t=0.821)$ and the ambiguity of the role $(\beta=0.156, t=1.323)$ have not found to be significant. 
Table 4: Results of Path Coefficient

\begin{tabular}{|c|c|c|c|c|c|}
\hline & $\begin{array}{l}\text { Path } \\
\text { Coefficient }\end{array}$ & $\begin{array}{l}\text { Std } \\
\text { error }\end{array}$ & $\begin{array}{l}\mathrm{T} \\
\text { value }\end{array}$ & $\begin{array}{l}\text { P } \\
\text { Values }\end{array}$ & Decision \\
\hline H1: $\quad$ Technostress and Emotional & & & & & Supported \\
\hline Exhaustion & 0.809 & 0.029 & 28.274 & 0.000 & \\
\hline H1a: Job insecurity and & & & & & Supported \\
\hline Exhaustion & 0.146 & 0.087 & 1.677 & 0.047 & \\
\hline H1b: Privacy and Emotional Exhaustion & 0.058 & 0.071 & 0.821 & 0.206 & Not \\
\hline $\begin{array}{l}\text { H1c: Role ambiguity and Emotional } \\
\text { Exhaustion }\end{array}$ & 0.156 & 0.118 & 1.323 & 0.093 & $\begin{array}{l}\text { Supported } \\
\text { Not } \\
\text { Supported }\end{array}$ \\
\hline H1d: WH Conflict and Emotional & & & & & Supported \\
\hline Exhaustion & 0.278 & 0.106 & 2.617 & 0.005 & \\
\hline H1e: Work overload and Emotional & & & & & Supported \\
\hline Exhaustion & 0.198 & 0.095 & 2.094 & 0.018 & \\
\hline H2: Technostress and Proactive Coping & 0.281 & 0.181 & 1.554 & 0.060 & $\begin{array}{l}\text { Not } \\
\text { Supported }\end{array}$ \\
\hline $\begin{array}{l}\text { H3: Technostress and Reactive Coping } \\
\text { H4: Emotional Exhaustion and Proactive }\end{array}$ & 0.548 & 0.161 & 3.403 & 0.000 & $\begin{array}{l}\text { Supported } \\
\text { Supported }\end{array}$ \\
\hline Coping & 0.302 & 0.100 & 3.017 & 0.001 & \\
\hline $\begin{array}{l}\text { H5: Emotional Exhaustion and Reactive } \\
\text { Coping }\end{array}$ & 0.381 & 0.069 & 5.545 & 0.000 & Supported \\
\hline
\end{tabular}

Based on the findings, there are scientific evidences that confirm employees' emotional exhaustion is caused by technology. The technology which is supposed to function as the enabler has crossed the boundaries of the employees' life. Its functionality that allows work to be done outside the office and at flexible time also have created challenges to the employees in putting a clear separation between work and home. This could be inferred to how employees face work-home conflict and the frustration that their spouse and family members have to deal with. In addition, the availability of the technology and its ease of operations have caused employees to believe they are overburdened with their tasks, and they have to deal with more jobs than they have expected. A work by (Zhao et al., 2020) also discusses on the issue of technology and stress that may impact on workers' productivity. Likewise, taking the counter measures to cope with the emotional burden has been found to be a good move towards reducing the potential of mental challenges. However, it is interesting to note how employees react to the mental exhaustion. While there are significant evidences that proactive and reactive copings are the mechanism for reducing the emotional illness, only reactive coping was found to be workable as a method to reduce technostress. What the results suggest employees tend to act as a reaction in response towards the issue, and not taking any actions to create or control the technostress situations. Hence, it signals for why people like to take things as it is, even though they are well aware being in control is important.

\section{Conclusion}

The study explores the relationship between technostress, emotional exhaustion and coping strategy. The findings suggest technology that works as an enabler for ease of work has a profound effect towards mental health. With technology, it creates a blurring boundary 
between work and home, and the feeling of insecure towards the jobs and ambiguity of the roles. But one way to deal with the emotional exhaustion is by taking the counter measures of proactive and reactive coping. The findings suggest even though technostress leads to emotional exhaustion, how employees cope the mental challenges is extremely important. Hence, the study provides significant contextual means as a pathway for organizations to look for adequate strategies and creating awareness on the potential emotional burdens for the employees and organizational benefits. Likewise, the findings have contributed to the theoretical understanding of the essential roles of coping strategies in reducing emotional exhaustion, caused by technostress. As the present study is limited to path analysis, future research may look for comparisons between gender, or type of work and to suggest for a better coping strategy as an understanding on how technology as an enabler could be used for improving the quality of life.

\section{Acknowledgment}

Researchers would like to thank all members in the research group and to the Faculty of Business and Management, University Technology MARA for their continuous support throughout the guide and funding in this research and publication. 


\section{References}

Ansah, S. O., Azasoo, J. Q, Adu, I. N. (2016) Understand the effect of technostress on the performance of banking staff: International Journal of Business Continuity and Risk Management. Inderscience Enterprise Ltd Vol 6(3) page 222-237

Beaudry, A., \& Pinsonneault, A. (2005). Understanding user responses to information technology: A coping model of user adaptation. MIS quarterly, 29(3). https://doi.org/10.2307/25148693

Belcastro (1982) Burnout and its Relationship to Teachers' Somatic Complaints and Illnesses. SAGE Journal, Psychological Reports. Vol 50, Issue 3. https://doi.org/10.2466/pr0.1982.50.3c.1045

Belcastro, P. A., \& Hays, L. C. (1984). Ergophilia... ergophobia... ergo... burnout? Professional Psychology: Research and Practice, 15(2), 260-270. https://doi.org/10.1037/07357028.15.2.260

Brod, C. (1984). Technostress: The human cost of the computer revolution. Reading, MA: Addison-Wesley.

Caro, D. H. J., \& Sethi, A. S. (1985). Strategic Management of Technostress: The Chaining of Prometheus. Journal of Medical System 9(3), 291-304. https://doi.org/10.1007/BF00992568

Christian, Purwanto \& Wibowo. (2020). Technostress Creators on Teaching Performance of Private Universities in Jakarta During Covid 19, Technology Report of Kansai University Vol 62 (6)

Clark, K., and Kalin, S. (1996) Technostressed Out? How to Cope in the Digital Age. Library Journal, 121, 30-32.

Demerouti et. al., 2010. Burnout and Work Engagement: A Thorough Investigation of the Independency of Both Constructs Journal of Occupational Health Psychology 15(3):20922. DOI: $10.1037 / \mathrm{a} 0019408$

Dwyer, A. L., \& Cummings, A. L. (2001). Stress, self-efficacy, social support, and coping strategies in university students. Canadian Journal of Counselling, 35(3), 208-220

Fujimoto, Ferdous, Sekiguchi \& Sugianto. (2016). The effect of mobile technology usage on work engagement and emotional exhaustion in Japan, Journal of Business Reseach, Vol 69 (9), page 3315-3323. https://doi.org/10.1016/j.jbusres.2016.02.013

Gaudioso, F., Turel, O., \& Galimberti, C. (2017). The mediating roles of strain facets and coping strategies in translating techno-stressors into adverse job outcomes. Computers in Human Behavior, 69, 189-196. DOI: 10.1016/j.chb.2016.12.041

Greenglass, E., Fiksenbaum, L. (2009). Proactive coping, positive affect, and well-being: Testing for mediation using path analysis. European Psychologist, 14(1), 2939. https://doi.org/10.1027/1016-9040.14.1.29

Hair, J. F., Ringle, C. M., and Sarstedt, M. (2011), "PLS-SEM: indeed a silver bullet", Journal of Marketing Theory and Practice, Vol. 19 No. 2, pp. 139-151. https://doi.org/10.2753/MTP1069-6679190202

Halbesleben, J. R., and Bowler, W. M. (2007), Emotional exhaustion and job performance: the mediating role of motivation. Journal of Applied Psychology, 2009 2(1): p. 93-106. https://doi.org/10.1037/0021-9010.92.1.93

Hsiao, Shu \& Huang. (2017), Exploring the effect of compulsive social app usage on technostress and academic performance: Perspectives from personality traits. Telematics and Informatics Volume 34, Issue 2, Pages 679-690.

https://doi.org/10.1016/j.tele.2016.11.001 
Korzynski, P., Rook, C., Florent-Treacy, E., and Kets de Vries, M. (2020) The impact of selfesteem, conscientiousness and pseudo-personality on technostress. Vol 31 Issue 1. Internet Research. ISSN 1066-2243. DOI: 10.1108/INTR-03-2020-0141

La Montagne, A. D., Keegel, T., Louie, A. M., Ostry, A., \& Landsbergis, P. A. (2007). A systematic review of the job-stress intervention evaluation literature, 1990-2005. International journal of occupational and environmental health, 13(3), 268-280. doi: 10.1179/oeh.2007.13.3.268.

Lazarus, R. S. (1966). Psychological stress and the coping process. McGraw Hill.

Lazarus, R. S. (1993). From psychological stress to the emotions: A history of changing outlooks. Annual review of psychology, 44(1), 1-22.

https://doi.org/10.1146.annure.pc.44.020193.000245

Lazarus, R. S., \& Folkman, S. (1984). Stress, appraisal, and coping. Springer publishing company.

Maier, C., Laumer, S., Weinert, C., \& Weitzel, T. (2015). The effects of technostress and switching stress on discontinued use of social networking services: a study of Facebook use. Information Systems Journal, 25(3), 275-308. DOI: 10.1111/isj.12068

Maslach \& Jackson. (1981). The measurement of experienced burnout. Journal of Organisational Behaviour. Vol 2 (2). Page 99-113. https://doi.org/10.1002/job.4030020205

Michelle \& Larry. (1998) TechnoStress: Coping with Technology @Work @Home @Play

Molino, Cortese \& Ghislieri. (2017). New Technologies Smart, or Harm Work-Family Boundaries Management? Gender Differences in Conflict and Enrichment Using the JDR Theory. Frontiers in Psychology 8 (1070). https://doi.org/10.3389/fpsyg.2017.01070

Mooren, J. E. (2000), Why is This Happening? A Causal Attribution Approach to Work Exhaustion Consequences. Academy of Management Review Vol. 25, No. 2

Prabhakaran, A., \& Mishra, H. K. (2012). Technological change in libraries: the evolution of techno stress. Researchers World, 3(1), 131.

Qureshi, M. O., \& Sajjad, S. R. (2015). Emotional exhaustion and its correlation with job performance and job satisfaction in the Kingdom of Saudi Arabia. Mediterranean Journal of Social Sciences, 6(3 S1), 51. DOI: 10.5901/mjss.2015.v6n3s1p51

Rai, P., Rohatgi, J., \& Dhaliwal, U. (2019). Coping strategy in persons with low vision or blindness-an exploratory study. Indian Journal of Ophthalmology, 67(5), 669. doi: 10.4103/ijo.IJO_1655_18

Rosen, L. D., \& Weil, M. M. (1997). Technostress: Coping with technology work home play. New York: John Wiley \& Sons, Inc.

Schwarzer, R., \& Knoll, N. (2003). Positive coping: Mastering demands and searching for meaning. Positive psychological assessment: $A$ handbook of models and measures, 393409. https://doi.org/10.1037/10612-025.

Srivastava, S. C., Chandra, S., \& Shirish, A. (2015). Technostress creators and job outcomes: theorising the moderating influence of personality traits. Information Systems Journal, 25(4), 355-401. https://doi.org/10.1111/isj.12067

Tarafdar, M., Gupta, A., \& Turel, O. (2013). The dark side of information technology use. Information Systems Journal, 23(3), 269-275. https://doi.org/10.1111/isj.12015

Wanda, J., Orlikowski, Marcie, J. T. (1994) Windows of Opportunity: Temporal Patterns of Technological Adaptation in Organizations. https://doi.org/10.1287/orsc.5.1.98 
Weinert, C., Maier, C., Laumer, S., \& Weitzel, T. (2019). How do users respond to technostress? An empirical analysis of proactive and reactive coping. In Proceedings of the 52nd Hawaii International Conference on System Sciences. doi:10.24251/HICSS.2019.613

Wright, T. A., \& Cropanzano, R. (1998). Emotional exhaustion as a predictor of job performance and voluntary turnover. Journal of Applied Psychology, 83(3), 486493. https://doi.org/10.1037/0021-9010.83.3.486

Zhao, Xia., and Huang. (2020). Impact of technostress on productivity from the theoretical perspective of appraisal and coping processes. Science Direct, Information \& Management Volume 57, Issue 8. https://doi.org/10.1016/j.im.2020.103265 